Review began 01/19/2022 Review ended 02/03/2022 Published 02/11/2022

๑) Copyright 2022

Tasha et al. This is an open access article distributed under the terms of the Creative Commons Attribution License CC-BY 4.0. which permits unrestricted use, distribution, and reproduction in any medium, provided the original author and source are credited.

\section{Pneumatosis Intestinalis in a Patient With Asthma: A Case Report}

\author{
Tasniem Tasha ${ }^{1}$, Priyata Dutta ${ }^{2}$, Basher Atiquzzaman ${ }^{3}$ \\ 1. Internal Medicine, Rajshahi Medical College, Rajshahi, BGD 2. Physiology, University of Michigan, Ann Arbor, USA \\ 3. Internal Medicine, University of Central Florida, Orlando, USA
}

Corresponding author: Tasniem Tasha, tsnmtasha@gmail.com

\section{Abstract}

Pneumatosis intestinalis (PI) is a rare condition marked by gas-filled cysts in the submucosa and subserosa of the intestine. It can be idiopathic or linked to several illnesses, including gastrointestinal, pulmonary, collagen vascular disease, organ transplantation, and immunodeficiency. Herein we present a relatively rare case of PI in a 74-year-old man with a childhood history of asthma, which was found during routine colonoscopy.

Categories: Internal Medicine, Gastroenterology

Keywords: colonic wall, screening colonoscopy, gastrointestinal (gi), asthma, pneumatosis intestinalis

\section{Introduction}

Pneumatosis intestinalis (PI) is characterized by gas-filled cysts in the intestinal submucosa and subserosa. It is a rare disease, and the incidence rate is $0.03 \%$ in the general population [1]. PI was first described by DuVernoi in 1783 and later subclassified by Koss in 1952 [2]. It is classified into primary or idiopathic type (15\%), and secondary type ( $85 \%$ ) caused by various predisposing factors [3-4]. The secondary type consists of various etiologies like gastrointestinal, pulmonary, collagen vascular, organ transplantation, and immunodeficiency $[2,5]$. PI can occur anywhere in the gastrointestinal tract distal to the stomach. In a retrospective review of 97 patients, the location of pneumatosis was as follows: colon $46 \%$, small bowel $27 \%$, stomach $5 \%$, and $7 \%$ in both small and large intestines [6]. Mostly subserous cysts are present in the small bowels; on the contrary submucous localizations prevail in the colon wall [7]. Most cases of PI are asymptomatic and never come to medical attention. The most common manifestations in patients with small intestinal pneumatosis are vomiting, abdominal pain, weight loss, and diarrhea. On the other hand, diarrhea, hematochezia, abdominal pain, abdominal distension, and constipation are the most common symptoms of large intestinal pneumatosis [7-8]. PI associated with asthma is extremely rare. In this report, we present a case of PI associated with asthma in an otherwise healthy adult, which was detected during the routine colonoscopy.

\section{Case Presentation}

A 74-year-old Hispanic man presented with a medical history of well-controlled asthma since childhood to the gastroenterology outpatient clinic in Florida with the complaint of abdominal bloating for three months without any significant clinical history of abdominal distention, abdominal pain, bloody stool, tenesmus, or weight loss. A physical examination revealed no abnormalities. He had a history of smoking one pack per day for 20 years and has a history of asthma from childhood which is well controlled by anti-asthmatic medications (fluticasone-formoterol inhaler). A screening colonoscopy revealed the existence of multiple submucosal nodular projections in the wall of descending colon, some of which were transparent (Figure 1). Therefore, the diagnosis of PI was made. After being punctured by the needles, the bubbles collapsed, and the mucosa was removed and sent for histopathological examination. The patient's symptoms resolved within three months after conservative medical treatment (antibiotics, elemental diet). On six months of follow-up, his gastrointestinal symptoms had been resolved and he remained asymptotic. 


\section{Cureus}
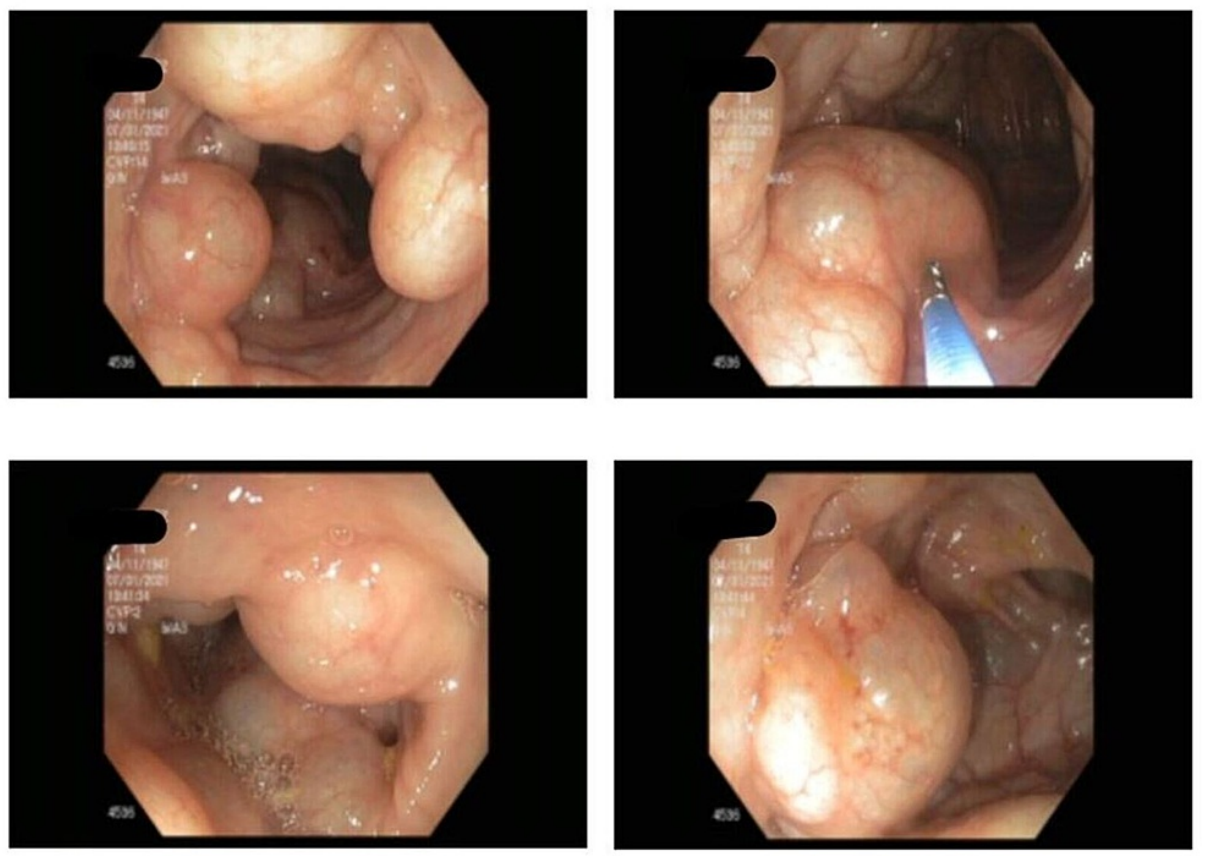

FIGURE 1: Colonoscopic images of PI at the mid and distal descending colon.

$\mathrm{PI}$, pneumatosis intestinalis

\section{Discussion}

Pneumatosis intestinalis is a rare disease and is still poorly understood. Although previously PI was associated with postoperative complications of abdominal surgery, the prevalence has been increasing due to greater use of colonoscopy. It typically presents in the fifth to eighth decades of life $[6,9]$.

The pathogenesis of PI is yet to be clearly understood, however, it is considered multifactorial. Some cases of PI are incidental findings associated with a benign etiology, whereas in others, it presents as a lifethreatening condition.

The primary type which is not associated with other diseases accounts for $15 \%$ of cases, and the secondary type accounts for the remaining $85 \%$ of cases [3-4]. Some predisposing factors that are associated with PI are mentioned in Table $1[2,5,8]$.

\begin{tabular}{|c|c|}
\hline Types & Factors \\
\hline Pulmonary disorders & Asthma, chronic obstructive pulmonary disease, cystic fibrosis, positive pressure mechanical ventilation \\
\hline Mucosal disruption & $\begin{array}{l}\text { Peptic ulcer disease, Crohn's disease, ulcerative colitis, abdominal surgery, gastrointestinal endoscopy, ionizing } \\
\text { radiation }\end{array}$ \\
\hline Infections & $\begin{array}{l}\text { Clostridium difficile, tuberculosis, AIDS-associated enterocolitis (cryptosporidium, cytomegalovirus, } \\
\text { mycobacterium avium), SARS-CoV-2 }\end{array}$ \\
\hline $\begin{array}{l}\text { Immunological } \\
\text { disturbance }\end{array}$ & AIDS, steroid, amyloidosis, scleroderma, solid organ transplantation, lymphoproliferative disorder \\
\hline
\end{tabular}

TABLE 1: Common factors associated with PI.

$\mathrm{PI}$, pneumatosis intestinalis; SARS-CoV-2, severe acute respiratory syndrome coronavirus 2; AIDS, acquired immune deficiency syndrome 
Gas dissects into the intestinal wall from either the luminal surface through breaches in the mucosa or through the serosal surface by tracking along mesenteric blood vessels, according to the mechanical hypothesis. Once, inside the bowel wall, the gas might advance along the mesentery to distant locations. The mechanical theory explains the association of PI with obstructive pulmonary diseases. Coughing in these patients may induce alveolar rupture, allowing air to travel through blood vessels into the mediastinum, diaphragm, and finally to the mesenteric root. Once air has obtained access to the mesenteric root, it may travel via the mesenteric blood vessels and eventually through the intestinal wall [9-10]. In our case, the patient has a long-standing history of chronic asthma without other predisposing factors. We assumed that the severe cough because of asthma caused an abrupt increase in the intraluminal pressure in the intestinal wall susceptible to mechanical injury, leading to breaking in the mucosa of the intestinal wall and PI developed [10].

Bacterial theory reports that PI is caused by gas-forming bacteria getting access to the submucosa via breaks in the mucosa. This theory can be explained by the fact that the gas-forming bacillus Clostridium perfringens is linked to PI, and that this can be resolved with antibiotic treatment. Luminal bacteria produce excessive amounts of hydrogen gas through the fermentation of carbohydrates and other foods, according to biochemical theory. Gas can flow right through the mucosa and be trapped in the submucosal tissue when the pressure of the gas within the intestinal lumen rises [11-12].

The most common symptoms of PI include diarrhea, stomach pain, abdominal distension, loss of appetite, weight loss, constipation, flatulence, and tenesmus; however many individuals may be asymptomatic [5]. In most cases, such as ours, physical examinations reveal no significant symptoms or aberrant results. Simple $\mathrm{X}$-rays, abdominal sonography, CT, and colonoscopy are all common diagnostic techniques for PI.

Patients who are asymptomatic do not need to be treated. The underlying cause of PI should be treated regardless of the appearance of symptoms. Antibiotics and an elemental diet may be considered for patients with mild symptoms [12-15]. Inhalation of oxygen therapy, antibiotics, and an elemental diet is used in the case of moderate to severe symptoms. Hyperbaric oxygen therapy can be provided for three days to patients who have persistent symptoms [16-17]. Furthermore, surgery is reserved for patients who continue to have symptoms despite medical treatment or who develop intestinal obstruction or perforation due to PI [3].

\section{Conclusions}

Pneumatosis intestinalis (also called intestinal pneumatosis, pneumatosis cystoid intestinalis, pneumatosis coli, or intramural bowel gas) is pneumatosis of an intestine, that is, gas cysts in the bowel wall. The pathogenesis of PI is poorly understood and is likely multifactorial. This patient was diagnosed with asthma from his early childhood that was well controlled with anti-asthmatic medications. He presented with abdominal bloating and was followed by routine colonoscopy for further evaluation and was diagnosed with PI. In our case, we tried to highlight the association of asthma with PI according to the mechanical theory. PI is a rare condition, however, if a patient with a chronic pulmonary disease such as asthma presented with abdominal symptoms like abdominal bloating as in our case should arise suspicion of PI.

\section{Additional Information \\ Disclosures}

Human subjects: Consent was obtained or waived by all participants in this study. Conflicts of interest: In compliance with the ICMJE uniform disclosure form, all authors declare the following: Payment/services info: All authors have declared that no financial support was received from any organization for the submitted work. Financial relationships: All authors have declared that they have no financial relationships at present or within the previous three years with any organizations that might have an interest in the submitted work. Other relationships: All authors have declared that there are no other relationships or activities that could appear to have influenced the submitted work.

\section{References}

1. Di Pietropaolo M, Trinci M, Giangregorio C, Galluzzo M, Miele V: Pneumatosis cystoides intestinalis: case report and review of literature. Clin J Gastroenterol. 2020, 13:31-36. 10.1007/s12328-019-00999-3

2. Koss LG: Abdominal gas cysts (pneumatosis cystoides intestinorum hominis); an analysis with a report of a case and a critical review of the literature. AMA Arch Pathol. 1952, 53:523-549.

3. Greenstein AJ, Nguyen SQ, Berlin A, et al.: Pneumatosis intestinalis in adults: management, surgical indications, and risk factors for mortality. J Gastrointest Surg. 2007, 11:1268-1274. 10.1007/s11605-0070241-9

4. Gelman SF, Brandt LJ: Pneumatosis intestinalis and AIDS: a case report and review of the literature . Am J Gastroenterol. 1998, 93:646-650.10.1111/j.1572-0241.1998.183_b.x

5. Knechtle SJ, Davidoff AM, Rice RP: Pneumatosis intestinalis. Surgical management and clinical outcome . Ann Surg. 1990, 212:160-165. 10.1097/00000658-199008000-00008

6. Morris MS, Gee AC, Cho SD, Limbaugh K, Underwood S, Ham B, Schreiber MA: Management and outcome of pneumatosis intestinalis. Am J Surg. 2008, 195:679-682; discussion 682-683. 10.1016/j.amjsurg.2008.01.011

7. Jamart J: Pneumatosis cystoides intestinalis. A statistical study of 919 cases . Acta Hepatogastroenterol (Stuttg). 1979, 26:419-422. 


\section{Cureus}

8. Wu LL, Yang YS, Dou Y, Liu QS: A systematic analysis of pneumatosis cystoids intestinalis . World J Gastroenterol. 2013, 19:4973-4978. 10.3748/wjg.v19.i30.4973

9. Pieterse AS, Leong AS, Rowland R: The mucosal changes and pathogenesis of pneumatosis cystoides intestinalis. Hum Pathol. 1985, 16:683-688. 10.1016/s0046-8177(85)80152-0

10. Keyting WS, McCarver RR, Kovarik JL, Daywitt AL: Pneumatosis intestinalis: a new concept . Radiology. 1961, 76:733-741. 10.1148/76.5.733

11. Yale CE, Balish E, Wu JP: The bacterial etiology of pneumatosis cystoides intestinalis . Arch Surg. 1974, 109:89-94. 10.1001/archsurg.1974.01360010067017

12. Ellis BW: Symptomatic treatment of primary pneumatosis coli with metronidazole . Br Med J. 1980, 280:763764. 10.1136/bmj.280.6216.763-a

13. Tak PP, Van Duinen CM, Bun P, Eulderink F, Kreuning J, Gooszen HG, Lamers CB: Pneumatosis cystoides intestinalis in intestinal pseudoobstruction. Resolution after therapy with metronidazole. Dig Dis Sci. 1992, 37:949-954. 10.1007/BF01300397

14. van der Linden W, Marsell R: Pneumatosis cystoides coli associated with high H2 excretion. Treatment with an elemental diet. Scand J Gastroenterol. 1979, 14:173-174. 10.3109/00365527909179864

15. Johnston BT, McFarland RJ: Elemental diet in the treatment of pneumatosis coli . Scand J Gastroenterol. 1995, 30:1224-1227. 10.3109/00365529509101636

16. Holt S, Gilmour HM, Buist TA, Marwick K, Heading RC: High flow oxygen therapy for pneumatosis coli . Gut. 1979, 20:493-498. 10.1136/gut.20.6.493

17. Forgacs P, Wright PH, Wyatt AP: Treatment of intestinal gas cysts by oxygen breathing . Lancet. 1973, 1:579582. 